\title{
Streptomyces somaliensis
}

National Cancer Institute

\section{Source}

National Cancer Institute. Streptomyces somaliensis. NCI Thesaurus. Code C86814.

A species of aerobic, Gram positive, filamentous bacteria in the phylum Actinobacteria.

This species is spore forming, does not demonstrate growth or metabolism of

carbohydrates and can use organic esters as carbon sources. S. somaliensis is a known pathogen that can cause mycetoma. 